\title{
An IoT Based Smart Inverter Design
}

\author{
Veena B, Subhashree S, Swathi S, Revathi R \\ Department of Electrical Engineering \\ Dr. T. Thimmaiah Institute of Technology, \\ Kolar Gold Fields - 563120, Karnataka, India. \\ veena@drttit.edu.in
}

\begin{abstract}
The cutting-edge change in power has become the top focal part required to fuel an economy. Every territory like organizations, homes, and therefore the organization itself is overwhelmingly guided subject to the force for its smooth working. Hereafter, it's time we use manageable force sources so on scale down weight on power systems. In like manner, it's basic to talk to significant expert within the possibility of essentialness age using limitless sources and imperativeness storing during a profitable manner relative back the load on power networks. Imperativeness amassing finishes up being valuable during emergencies like floods, tempests, disappointment, etc. which degree in long power cuts. The people impact has moreover happen the time between an influence lack and important power cuts. However, with the reliably rising mechanical advances, the inverter is foreseen to be far more splendid than it's by and by. a wise inverter must use supportable force source to charge its battery, it need to be adaptable and arranged to send and obtain messages quickly, furthermore as offer data with the Thus exist augmentation for retrofitting the overall inverters to stipulate all of them the more effectively to grasp by demonstrating the battery voltage and moreover giving information on the run-time of his piles while using the battery, which container in like manner advance ground-breaking use of reachable essentialness by the customer .
\end{abstract}

Keywords:Smart inverter, ESP8266 Wi-Fi module, IoT, Blynk server, Arduino mega 2560 .

\section{$1 \quad$ Introduction}

On account of the financial transformation, quality has developed thanks to the best basic detail required to fuel a monetary framework. Each period of society like enterprises, homes, and during this way, the administration itself is firmly guided into quality for its simple working. Be that because it may, populace extension has prompted expanding association in power. Contamination on account of ordinary power assets is as of now at an unequaled extreme. Thus, it is time we utilize sustainable power source advantages for be prepared to scale back pressure on power networks. Along these lines, its miles remarkably essential to the mindfulness at the- 
thought of vitality period the use of inexhaustible resources and quality stockpiling of intensity productive to decrease the strain on quality networks. Vitality carport comes in accessible during crises like floods, storms, framework disappointment then forward which causes long vitality cuts. The populace blast has furthermore happen during a top quality shortage and significant vitality cuts. In any case, with the everdeveloping mechanical advances, the inverter is anticipated to be an entire parcel more intelligent than its miles now. a way for doing it to allow the supporter to screen its notoriety distantly. From this we for the foremost part consider observing the battery charging status, showing the run-time of the hundreds and controlling of burdens remotely. Inverters are found in many families and businesses are controlled with the help of non-inexhaustible. Quality sources and are crude in their design and use. Most buyers are gotten off-secure while the inverter's battery ceases to exist on the grounds that the predominant inverters don't have the power to alarm the clients round the vitality utilization and battery ways of life last. an inexpensive inverter must utilize inexhaustible solidarity to require care of its battery, it need to be versatile and equipped for send and secure messages quick.

\section{Literature Survey}

The inverter and switches are generally found in many families today . Usage of an inexpensive inverter that utilizes $\mathrm{Wi}$-Fi to interface during a two-route correspondence with the client of both, the battery voltage of the inverter additionally as run time of the hundreds which the client decides to run. During this concept, the battery of the inverter is charged utilizing the sun based cluster making it's an ecoaccommodating force age. within the current framework, everything is observed and controlled physically. Just simple frameworks are there for power confirmation and cross-checking [1]. During this work, a bi-level PV based miniaturized scale network arrangement is proposed for low force private applications. The wellbeing gave at the networks, and houses aren't sufficient. Consequently, the minimal effort gadget, ace card measured PC that's Raspberry pi makes less space utilization which watchmen making an impact on the approved individual by the online application server. Increment the unwavering quality of the office flexibly for top burdens, and particularly for basic burdens [2].

Most as often as possible, vitality utilization is roofed by the age of Operated gadgets and during this way the joined battery inverter pack. During this undertaking, a sustainable power source from photovoltaic cells accessible a mix of inverters and batteries was mostly used to address gear issues. During the day, the atmosphere continually changes, along these lines the yield power in PV cells likewise changes. Here we've control and observing of producing plant execution, for a gentle yield, general barometrical conditions at a price. Reference control to the heap input source is finished by a microcontroller utilizing IoT. Inverters and switches are regular in most family applications today. During this text, be that because it may, we mention the usage of coordinated inverters with IoT [3]. Sunlight based fueled inverters that connect with the clients utilizing Wi-Fi innovation and advise clients about the battery the 
voltage of the inverter and during this way, commonly that clients want to start. Moreover, remote burden the executives is directed to upgrade vitality productivity and improve human solace. This work utilizes an Arduino UNO microcontroller card that bolsters ATmega328P and MCU side hubs running on Wi-Fi module ESP8266. During this current period of shrewd activity of electronic gadgets have without a doubt made an exceptional improvement in our lives [4] [7].

The innovation likewise causes us to enhance complex. During this point and age, there is a deficiency of common assets, and thus a scarcity inside the force provided through these force matrices. During this paper, a few of keen inverters frameworks that expand the essential lifetime of A battery which is extremely valuable during long and memorable force blackouts. By orchestrating $\mathrm{AC}$ yield voltages from different voltage levels [5] [6], segment waveforms is usually gotten that approach the sinusoidal waveform with insignificant symphonious contortion, during this manner diminishing channel necessities[8][9].

\section{Proposed Work}

In this work we utilize the unpreventable Wi-Fi headway, to form the present inverters dynamically skillful and clearer. The accessible choices for much away improvements are Wi-Fi, Bluetooth, GSM, and so on. The longing is that normalization will address that issue which the contraptions will offer a consistent encounter for the top client. Bluetooth may be a short segment distant headway found in many telephones, with low trade speed. All the problems with Bluetooth were comprehended with WiFi progression. The headway is most normally wont to interface Internet changes to gadgets like PCs, tablets, and telephones; in any case, it'll when all is claimed in done be utilized to relate together any two equipment divides. Wi-Fi switches are by and by introduced in everyone's homes and even Mobile gadgets can give out Wi-Fi signals utilizing the reduced structure's web. This framework needn't sit around idly with another additional module to be introduced; henceforth, Wi-Fi is seen as a humble and constantly adaptable reaction for home The ESP8266 is often changed in both Access point mode and Server mode. In area mode, it interfaces with an almost Wi-Fi to accompany the online, after which it can talk with any module identified with the online. The GUI was made utilizing Android studio for Mobile App The client can get to the knowledge utilizing the GUI and control the tons of the house also

\section{$4 \quad$ Methodology}

Set up of the model of the framework 


\subsection{Solar panel}

The photovoltaic module, referred to all the more generally as the sunlight-based board, is utilized as a part in a bigger photovoltaic framework to offer power for business and private applications. Since a solitary photovoltaic module can just create a restricted measure of intensity, numerous establishments contain a few modules or boards and this is referred to as a photovoltaic cluster is as appeared in figure 2 .

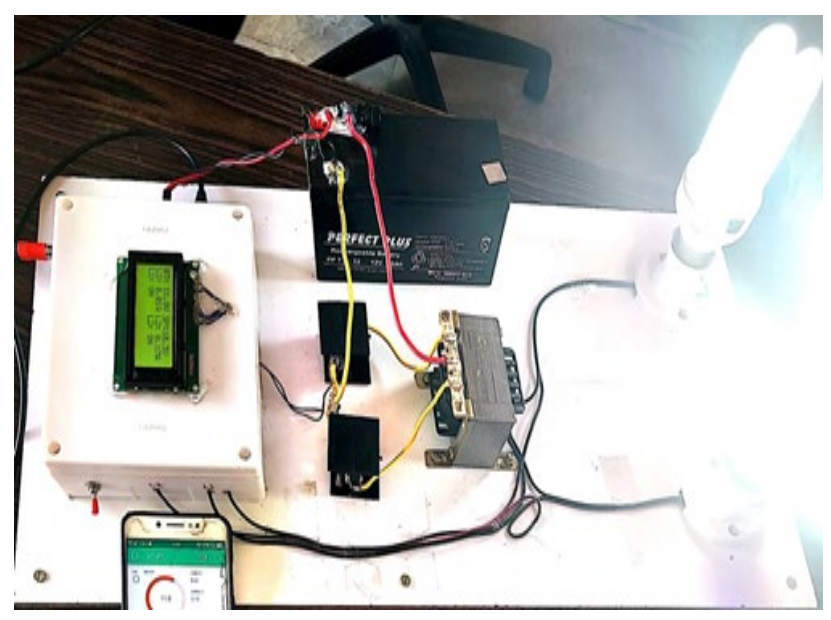

Fig 1: Arrangement of smart inverter3. 12v Rechargeable Battery

\subsection{Lead-corrosive}

Lead-corrosive batteries are broadly utilized in any event, when flood current isn't significant and different structures could give higher vitality densities. Lead-corrosive are generally utilized for capacity in reinforcement power supplies in mobile phone towers, high-accessibility settings like emergency clinics, and independent force frameworks. For these jobs, altered renditions of the standard cell might be utilized to improve capacity times and lessen upkeep prerequisites

\subsection{Driver Circuit}

A Darlington pair is two semiconductors that go about as a solitary semiconductor however with an a lot higher current addition as demonstrated figure 2. Semiconductors have a trademark called current increase. This is alluded to as its hFE. The measure of current that can go through the heap when associated with a semiconductor that is turned on rises to the info current $\mathrm{x}$ the increase of the semiconductor (hFE). The current increase fluctuates for various semiconductor and normally it might be 100 . This would imply that the current accessible to drive the heap would be multiple times bigger than the contribution to the semiconductor. 


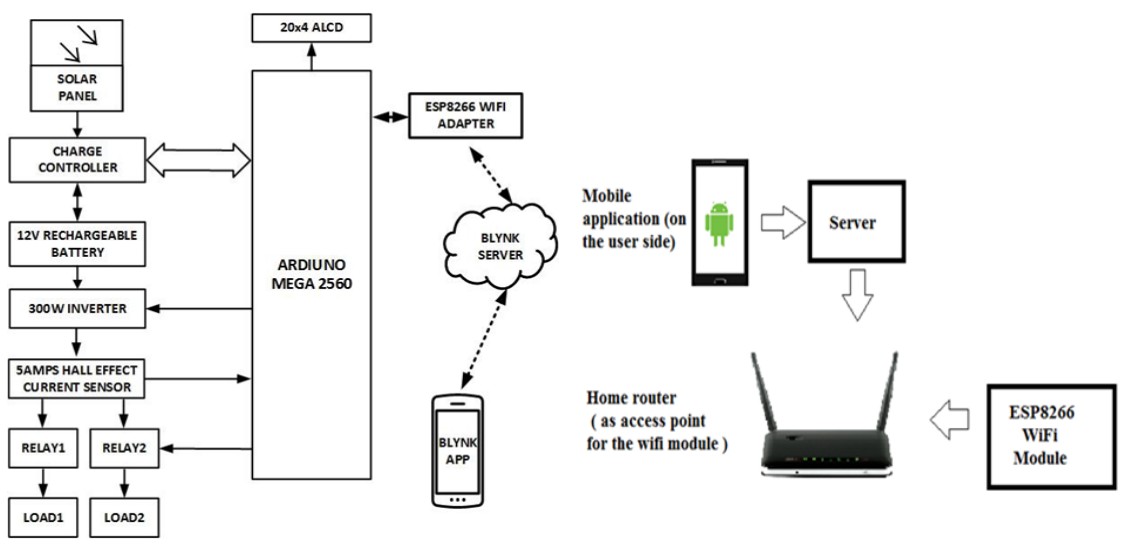

Fig 2: Block diagram of the equipment arrangement \&Useful Block outline of exchanging unit

\section{Implementation}

From sun-based board the vitality is provided to the charge controller which as a DC to DC buck converter and a voltage controller LM2965 where it is provided to the Arduino board through the transfer and furthermore accuses the battery of $12 \mathrm{v}$. The voltage signal is given to the inbuilt oscillator which has Darlington pair circuit and afterward the sign is driven by the MOSFET driver circuit and afterward ventured up to $220 \mathrm{v}$ AC gracefully utilizing a stage up transformer 0 to $220 \mathrm{v}$ and the heaps (1 and 2) are associated utilizing transfers and a $5 \mathrm{~A}$ ebb and flow sensor and the controlling activity is done remotely utilizing ESP8266 wifi handset which works at 3.3v. It interfaces with the Blynk worker and the yield is additionally shown on the LCD show and on the advanced mobile phone through Blynk application.

\section{Conclusion}

Through this work, we had the option to suitably execute an IoT based Smart inverter by retrofitting a current inverter with new functionalities, for example, bidirectional correspondence with the client. At the hour of a force cut, the client can remotely control loads subject to his needs. He can in like way check his battery voltage to avoid being found resting when the battery completely debilitates out with no sign. This model gives us a critical perception into the working of a free and solid framework for home robotization and watching power utilization of family machines. This structure requires essentially at early stage energy for sun-controlled board and the amazing inverter framework is made easily. A client conveys enough centrality for 
oneself and utilizations it as necessities be with a condition especially organized structure. At whatever point reached a framework, this endeavor can be identified with the cross-area, where clients can sell or purchase the force made from others, making it widely continuously changing. This can be finished utilizing net metering. Besides, since this work is bound to a LAN, port sending can be acknowledged to control the heaps in any case, when identified with a substitute structure.

\section{References}

1. Megha A Joshi, Kavya Shree S proposed "Smart inverter integrating with Raspberry PI", IEEE Trans. vol. 6, on Management and applied science, May 2017.

2. Santosh Kumar N, Shashi Kumar B, Suresh B and Vignesh S Proposed "IoT based Smart Inverter", on advanced science, vol. 2, June 2017.

3. Ningana goudaBiradar, Dr. BaswarajGadgay, VeereshPujari Proposed "IoT based smart inverter", IEEE Trans. on applied science, vol. 5, June 2017.

4. Raja Gopal V. Koushik, D. Naveen Kumar, S. Vinay raj N, Dr. RangaiahLeburu proposed "Smart Inverter", IJARIIE - ISSN (O), vol. 2, May 2017.

5. Ahmed, S.T., Sankar, S. \& Sandhya, M. Multi-objective optimal medical data informatics standardization and processing technique for telemedicine via machine learning approach. J Ambient Intell Human Comput (2020). https://doi.org/10.1007/s12652-02002016-9

6. Ahmed, S.T., Sandhya, M. \& Sankar, S. TelMED: Dynamic User Clustering Resource Allocation Technique for MooM Datasets Under Optimizing Telemedicine Network. Wireless PersCommun 112, 1061-1077 (2020). https://doi.org/10.1007/s11277-02007091-x

7. S. T. Ahmed and S. Sankar, "Investigative Protocol Design of Layer Optimized Image Compression in Telemedicine Environment", Procedia Computer Science, vol. 167, pp. 2617-2622, 2020, [online] Available: https://doi.org/10.1016/j.procs.2020.03.323

8. J. Dafni Rose, K. Vijayakumar and S. Sakthivel, "Students performance analysis system using cumulative predictor algorithm", Int. J. Reasoning-based Intelligent Systems, Vol. 11, No. 2, 2019.

9. Vijayakumar. K, Nawaz Sherif. T, Gokulnath.S, “Automated Risk Identification using Glove algorithm in Cloud Based Development Environments", International Journal of Pure and Applied Mathematics Volume 117 No. 162017. 
